Copyright 2001 Sage Publications

This is the author-manuscript version of this paper. First published in:

Higgs, Helen and Worthington, Andrew (2001) Consumer preferences and water charging options in a large urban municipality: a case study. Public Works Management and Policy 5(3):pp. 209-217.

\title{
CONSUMER PREFERENCES AND WATER CHARGING OPTIONS IN A LARGE URBAN MUNICIPALITY: A CASE STUDY
}

\author{
HELEN HIGGS \& ANDREW WORTHINGTON \\ Queensland University of Technology
}

This paper uses limited dependent variable techniques to model the decision-making process in a dual-pricing household water system as employed in Brisbane, Australia. In this system, households could initially choose to remain on a standard rateable value principle of payment for water or move to a volumetric/user-pays system. Because of uncertainty associated with future household water demand, the option to remain on the existing system has value and is thereby incorporated into the appropriate decision-making model. A number of property/household characteristics are found to influence the choice of water charging system along with the value of the option. These include property size and rateable value, the number of household members, the type of garden vegetation, and the presence of various household appliances.

$\mathrm{W}$

ater utilities in Australia have undergone a widespread program of institutional and administrative reforms during the 1990s, the large majority of which were directed at improving aspects of management and operational performance. For instance, in February 1994, the Council of Australian Governments (COAG) agreed to develop a 'strategic framework' for water reform and in April 1995, governments agreed to bring this COAG strategic framework within the ambit of the National Competition Policy (NCP) process. The framework commits governments to several administrative reforms. These include consumptionbased and two-part charging, full cost recovery (with subsidies made transparent), separate identification and funding of community service obligations (CSOs), the introduction of trading in rural water entitlements and the allocation of water for the environment as a legitimate use of 
water resources.

A key feature of these reforms has been changes to the pricing of urban water services. Consumption-based charging has been progressively introduced and property-based charges increasingly phased out. The trend toward consumption-based water charges is generally thought to have encouraged consumers to reduce their water use. Not only does this defer the need for additional infrastructure to satisfy growing demand, but also reduces the harmful environmental effects of wastewater and sewerage effluent disposal. It has been estimated that approximately 50 percent of urban water authority revenues were raised from usage charges in 1996/97.

One interesting characteristic of the newly implemented water charging system in Australia has been the use of a dual-pricing model by some water authorities. Normally, water authorities have a choice of different types of water pricing - uniform, increasing block rates, decreasing block rates or some combination of these - which are usually selected so as to maintain equity among customers and to reduce total water usage. In the move to consumption-based charges the Brisbane City Council (Australia's largest local government body) adopted a parallel pricing system including both 'rateable value' and 'user-pays'. Such parallel pricing systems are not unknown elsewhere. Sydney Water used an identical interim model in the move to user-pays and Cold Lake Alberta offers a choice between a flat or metered rate. Similarly, in the United Kingdom the Department of the Environment, Transport and the Regions' 1998 consultation paper Water Charging in England and Wales: A New Approach highlights customer choice of charging system as an important element in the switch to water usage on a measured basis. Further afield, consumer choice between a fixed or a variable charge system is commonplace in the telecommunication and electricity industries [see, for instance, Kridel et al. (1993).

In the case of Brisbane, and at the time of introduction, the pre-existing rateable value system consisted of a fixed charge per annum of $\$ 150$ (Australian dollars) plus a percentage $(0.432 \%)$ of the rateable (unimproved capital) value of the property. The user-pays system consisted of a fixed charge of $\$ 240$ per annum plus an increasing block price schedule of $\$ 0.15$ per kilolitre for the first 175 kilolitres and $\$ 0.45$ per kilolitre thereafter. Subsequently, the fixed charge decreased to $\$ 172.30$ per annum, though the marginal price increased to $\$ 0.30$ per kilolitre for the first 175 kilolitres and then $\$ 0.60$ per kilolitre. All households were given the option to go over to the user-pays system. However, this decision, once made, was irreversible.

The progressive introduction of a user-pays water supply in Brisbane has obvious efficiency, equity, revenue and infrastructure considerations. Household consumption dropped from 443 
kilolitres in 1996/97 under the valuation-based charging system to 280 kilolitres by 1999/00. And this fall in water consumption effectively delayed the planned 1998/99 \$36 million upgrade of the city's major water treatment plant. The shift to user-pays by individual properties has also generally been regarded as so successful that a similar policy has been extended to high-density development residents and body corporates. Of the 6000 group titles in Brisbane 2150 are unmetered, 3400 have a head meter at the property with no individual property meters, 200 have a head meter and individual meters, with the remainder having individual meters only. The option scheme here entails the retention of the valuation-based system, individual meters or a metered charge applied equally across all residents. It is generally expected, as with the earlier individual property scheme, that the majority of users will pay less for water consumption under a metered scheme.

The adoption of a parallel pricing system including both 'rateable value' and 'user-pays' charges by the Brisbane City Council provides an opportunity to examine some interesting aspects of household decision-making. On the one hand, the decision model for a household to choose between these alternatives can be investigated using standard qualitative techniques. The key feature is that the choice of water charging system will depend on the level of expected water consumption, which in turn can be identified on the basis of measurable household and property characteristics. However, the existence of the option to remain on the rateable value schedule also implies that the choice model should examine the premium that each household is willing to pay to maintain this status. Because consumers are generally uncertain of the future demand for water this option has value, and therefore the standard framework should be adapted to reflect this uncertainty. This is important because high option values may explain some of the reticence of consumers moving to user-pays and knowledge of these values may help the design of more efficient and equitable water-charging systems. The purpose of the current paper is to gauge the empirical significance of option values of this type in household water demand equations.

The organisation of the paper is as follows. The second section discusses the data requirements for estimation of the model of water charging choice and the set of socioeconomic variables to be included in this model are detailed. The third section presents the results of this estimation. The paper ends with brief concluding remarks

\section{Empirical Methodology}

The information for the demand estimation is obtained from a survey of three hundred and 
fifty sample households in the Brisbane City Council area. The sample period is selected so as to correspond to the year when the dual-pricing system was introduced, and thereby reflects the period when uncertainty regarding the new user charges was highest. The survey data contains characteristics of the individual households, such as the rateable value of individual properties, suburb, number of males and females in the household, toilets/bathrooms in the household, soil type and yard size. In addition, each household's water consumption over the previous summer and two winters is obtained from council rate notices. Using this information, two objectives are set. First, provide estimates of the value of the option associated with the dual-pricing system, and second, incorporate this variable, along with other property and household characteristics, into a model of discrete choice.

In a nutshell, the concept of option value exists in the present context because consumers are uncertain of their future demand for water. Rational behaviour under these circumstances is to expect the consumer to be willing to pay a certain amount (the option price) to maintain the right to use the pre-existing service. Cicchetti and Freeman (1971), for example, defined option price in these circumstances as the maximum sum the individual is willing to forgo to preserve the option of the future demand for this service before the uncertainty about the future demand itself is resolved. The proposed option value is therefore the difference between the option price and the expected consumer surplus with a positive option value indicating risk averse behaviour. Conversely, Schmalensee (1972), Bishop (1982) and Freeman (1984; 1986) using a similar framework concluded that the option value could be positive, negative or zero, depending on the particular circumstances of the contingent market. Other early work in this area includes Krutilla et al. (1972), Arrow and Fisher (1974), Graham (1981) and Shilling et al. (1987).

In reference to Figure 1 let a household on the rateable value scheme be on the utility function $U_{r}$ with the linear budget constraint $Y_{r}$. The budget constraint is tangent to the utility function at point $A$ (the satiation point) with quantity consumed, $q_{r}$. The marginal price of additional water usage in this instance is zero. If the household switches over to the user-pays scheme the budget constraint becomes $Y_{u}$ with the marginal price for water depending on the amount of water consumed. In Figure 1, the budget constraint is tangent to the utility function $U_{u}$ (indicating a welfare gain, though welfare losses are also possible) at point $B$ with quantity consumed $q_{u}$. If the budget constraint under the user-pays scheme at the user-pays prices is moved tangentially along the utility function to the marginal price of zero then the derived income is termed by Vartia (1983) as the compensated income. The difference between this compensated income and the 
income under the rateable value principle is the monetary amount or the premium that the household is willing to pay to stay on the rateable value scheme. This amount can be used as a proxy for option value.

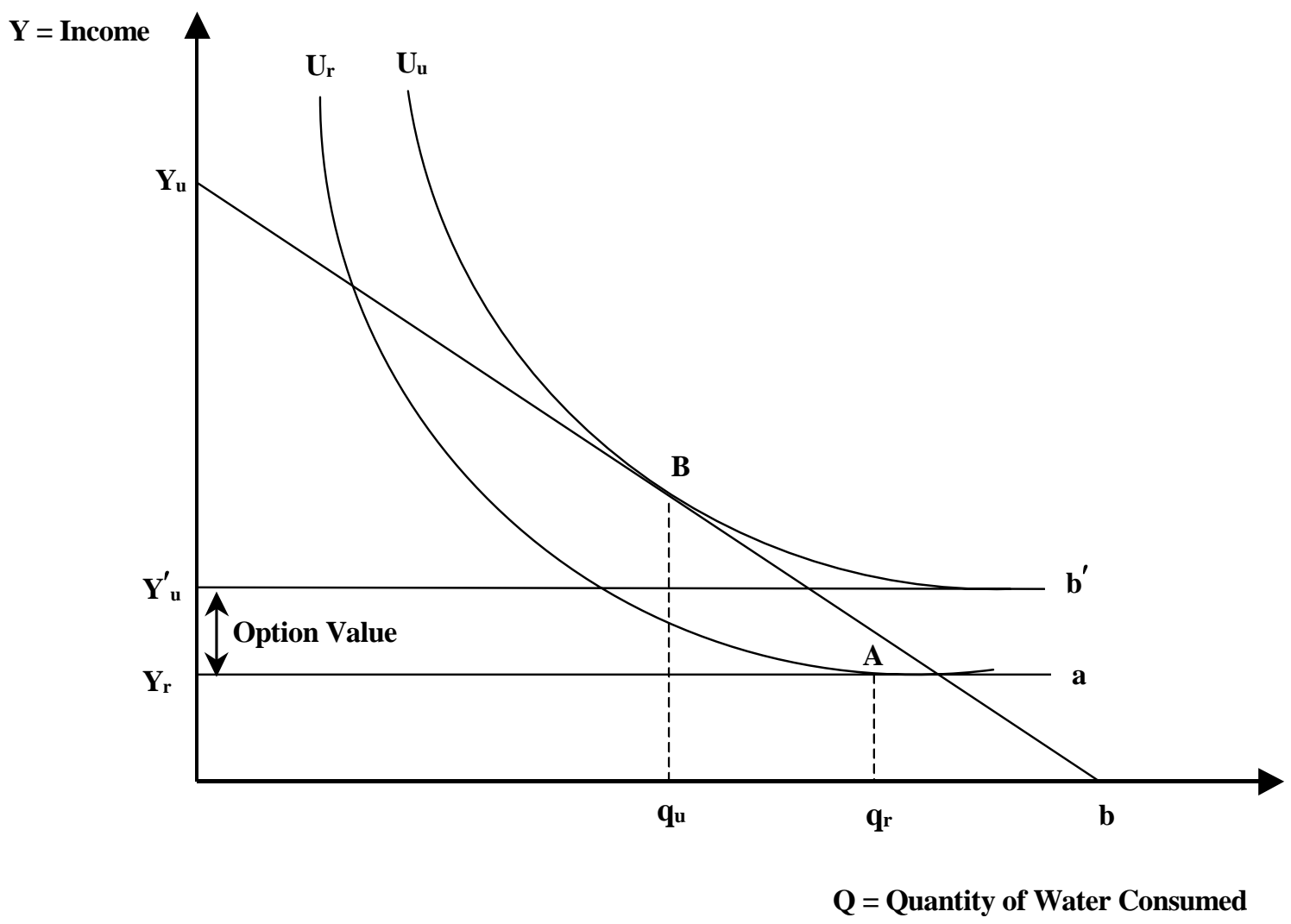

Figure 1. Compensated Income and Compensated Demand

Following Vartia (1983), the change in welfare and the compensated income in Figure 1 can be calculated from an ordinary demand function without the need to derive the corresponding utility function. Suppose the consumer aims to maximise a well-behaved utility function, $U(q)$, subject to a balanced budget constraint, $Y=p q=\Sigma p_{i} q_{i}$. The ordinary demand system, $D(p, Y)$, for a given price and income coordinate $\left(p_{0}, Y_{0}\right)$ and the corresponding ordinary demand equation $q_{0}=$ $D\left(p_{0}, Y_{0}\right)$ can be estimated. If the price is changed from $p_{0}$ to $p_{1}$, the compensated income $\left(\hat{Y}_{1}\right)$ can be determined:

$$
\begin{aligned}
\hat{Y}_{1} & =Y\left(p_{1}, q_{1}\right) \\
& =\min \left\{Y \mid Y=Y\left(p_{1} q_{1}\right) ; U(q)=U\left(q_{0}\right)\right\}
\end{aligned}
$$


and the Hicksian compensated demand is:

$$
\hat{q}_{1}=Q\left(p_{1}, q_{0}\right)=D\left(p_{1}, Y\left(p_{1}, q_{0}\right)\right)
$$

for any given vector of prices, $p_{1}$. The compensated income is the least income required to attain the same satisfaction as $q_{0}$ when the price has changed to $p_{1}$. A direct utility function $U(q)$ exists but is unknown. The compensated income can be derived from the ordinary demand system $D(p, Y)$. An algorithm of iterative processes is employed to move the price from $p_{0}$ to $p_{1}$ which generates the system of ordinary demand along the same indifference surface. When the iteration approaches the price $p_{1}$, the compensated income is derived. The difference between the compensated income and income under the rateable value scheme is defined as the option value.

In order to calculate the expected usage under the user-pays system (and the resulting compensated income and option value) an expected demand equation for water is initially specified with twenty-seven explanatory variables:

$$
\begin{array}{r}
W T R=f(V A L, I N C, M U P, S U M, Y E A R, H L D, P E N S, S P R, \\
N T V, V E G, S O I, P R P, Y R D, C A R, P B L, P A B, S P A, \\
W D G, S H W, B T H, B S N, L D Y, W S H, S N K, D U L, D S H, G D P)
\end{array}
$$

where daily water consumption in litres of the $i$ th household $(W T R)$ is a function (expected sign of the estimated coefficient in brackets) of the following sets of property/household characteristics. The first set of explanatory variables is considered to be a major determinant of household water consumption. These are the rateable value of the property $(+V A L)$, annual household income under a fixed charge per annum $(+I N C)$, the marginal water price under userpays $(+M U P)$, a seasonal dummy for summer $(+S U M)$, a dummy variable for the year $(+/-Y E A R)$ and the total number of household members $(+H L D)$. In the second set of explanatory variables, several other household/property characteristics are included to explain water consumption. These include: pensioner status $(-P E N)$, the number of times the lawn is watered per week $(+S P R)$, whether native vegetation $(-N T V)$ or vegetable crops $(+V E G)$ are grown, property $(+P R P)$ and yard $(+Y R D)$ size in metres, water absorbency of soil $(+S O I)$, the number of car washes per week $(+C A R)$, dummy variables for below ground pools $(+P B L)$, above ground $(+P A B)$ pools, spas $(+S P A)$ and wading pools $(+W D G)$, the number of showers $(+S H W)$, baths $(+B T H)$, hand-basins $(+B S N)$, laundries $(+L D Y)$, washing machines $(+W S H)$, and sinks $(+S N K)$, and dummy variables indicating the presence of dual-flush toilets $(-D U L)$, dishwashers $(-D S H)$ and garbage-disposal units $(+G D P)$. 
The final methodological requirement is to include the calculated option value, along with other characteristics thought to explain the choice of water charging system, in a model of discrete choice for which logit estimation is appropriate: The logit model represents the choice probability as:

$$
\begin{aligned}
P\left(y_{i}=1\right) & =F\left(X^{\prime} \beta\right) \\
& =\Lambda(X) \equiv \frac{1}{1+e^{-X^{\prime} \beta}}
\end{aligned}
$$

where $y_{i}=1$ if the household selects user-pays and zero otherwise, $\Lambda(X)$ is the logistic cumulative distribution function, $X$ is a vector of known explanatory variables, including the socioeconomic variables specified in (3), and $\beta$ is a vector of unknown parameters to be estimated.

\section{Results}

The analysis of the results is contained in two parts. The first part is concerned with the estimation of the option value associated with the dual-pricing water scheme. Table 1 provides the estimated coefficients and t-statistics of the parameters detailed in (3). The second part of the analysis is concerned with the actual model of consumer choice specified in (4). The estimated coefficients and t-statistics are provided in Table 2. Also included in Table 2 are statistics for joint hypothesis and likelihood ratio tests, and the results of a prediction success table for the dependent variable.

To start with, the water demand equation specified in (3) consists of twenty-seven explanatory variables. Because of the large number of explanatory variables, multicollinearity is an inevitable problem. To address this, principal components consisting of a linear combination of the twentyone lesser characteristic variables, are obtained. Ten principal components, where the eigenvalues of the correlation matrix are greater than one, are the established. The first column of Table 1 presents the estimated coefficients and t-statistics of an ordinary least squares regression employing the new expected demand equation. As shown, the estimated coefficient for the marginal price $(M U P)$ of the demand equation under uncertainty is positive, and inconsistent. With the presence of increasing block rates, the least squares estimate of the price variable is generally biased upwards. To address this problem, Terza and Welch (1982), Terza (1986) and Nieswiadomy and Molina (1989) used instrumental variable estimation to estimate the demand for water under decreasing and increasing block rates. 
Table 1. Estimated Water Demand Equation

\begin{tabular}{lrrr}
\hline Variable & Least squares & \multicolumn{1}{c}{$\begin{array}{c}\text { Instrumental } \\
\text { variable }\end{array}$} & $\begin{array}{c}\text { Transformed } \\
\text { instrumental } \\
\text { variable }\end{array}$ \\
\hline CONSTANT & $-37.555(-0.252)$ & $320.200(1.907)$ & $313.160(2.029)$ \\
VAL & $1.132(1.850)$ & $2.020(4.357)$ & $3.309(3.708)$ \\
INC & $6.984(3.668)$ & $7.197(3.788)$ & $7.904(4.309)$ \\
MUP & $11.297(1.992)$ & $-6.586(-2.304)$ & $-6.218(-2.479)$ \\
SUM & $278.200(4.629)$ & $182.510(4.140)$ & $163.180(3.885)$ \\
YEAR & $58.899(1.192)$ & $230.700(4.912)$ & $210.430(4.850)$ \\
HLD & $127.810(7.461)$ & $131.050(7.675)$ & $122.650(7.521)$ \\
$Z_{1}$ & $46.971(4.797)$ & $47.158(4.819)$ & $30.853(3.518)$ \\
$Z_{2}$ & $-15.573(-3.499)$ & $-15.254(-3.429)$ & $-10.987(-2.638)$ \\
$Z_{3}$ & $-25.776(-0.893)$ & $-24.295(-0.842)$ & $-8.384(-0.305)$ \\
$Z_{4}$ & $0.408(0.051)$ & $-0.498(-0.063)$ & $7.915(1.044)$ \\
$Z_{5}$ & $14.414(2.940)$ & $14.577(2.977)$ & $13.890(2.992)$ \\
$Z_{6}$ & $-7.199(-1.319)$ & $-6.978(-1.279)$ & $-11.793(-2.214)$ \\
$Z_{7}$ & $-24.110(-2.264)$ & $-23.854(-2.241)$ & $-28.296(-2.733)$ \\
$Z_{8}$ & $33.416(4.922)$ & $33.490(4.937)$ & $21.638(3.553)$ \\
$Z_{9}$ & $-34.732(-3.070)$ & $-34.549(-3.056)$ & $-16.659(-1.604)$ \\
$Z_{10}$ & $-44.964(-4.351)$ & $-45.260(-4.382)$ & $-22.432(-2.452)$ \\
\hline Notes: Figures in brackets are the corresponding t statistics with critical \\
values for the one-tailed test being $1.2816(\alpha=0.10), 1.6449(\alpha=0.05)$ and \\
$2.3263(\alpha=0.01)$ and for the two-tailed test being 1.645( $\alpha=0.10), 1.9600(\alpha$ \\
$=0.05)$ and 2.5758 $(\alpha=0.01)$ & & \\
\hline
\end{tabular}

The instrumental variable technique in this case has two steps. The first step is to obtain an instrumental variable for the user-pays marginal price. The observed water consumption for the user-pays households with the increasing block rate schedule is regressed on all explanatory variables, excluding the marginal price. This provides a linear approximation of the increasing block rate schedule, and is used to predict the quantities consumed by each of the user-pays households. The predicted quantities and the rate schedules are then used to predict the user-pays marginal price variable. The second step involves using the predicted user-pays marginal price as the instrumental variable for the observed user-pays marginal price in the second stage estimate of the demand equation. The expected demand equation for households on the user-pays schedule estimated on this basis is detailed in the second column in Table 1.

A further problem arises in that since the data are drawn from a predominantly cross-sectional sample, the presence of heteroscedasticity is likely. A Breusch-Pagan test detects a heteroscedastic pattern in the squared residuals and the rateable value $(V A L)$ variable. The 
calculated Breusch-Pagan test statistic is 8.7516 and the Chi-Square critical is 3.8415. A plot of the daily water demand $(W T R)$ and the rateable value $(V A L)$ variable shows that the variability of the disturbances decreases as the rateable value increases. The most appropriate transformation used to overcome heteroscedasticity in this instance is to divide all variables by the square root of $V A L$. The estimated coefficients for the transformed model are presented in the third column of Table 1. The Breusch-Pagan calculated test statistic for the transformed model is 2.652. Since the test statistic is less than the critical Chi-Square value of 3.8415 , heteroscedasticity has been removed from the model.

These final results can now be used as the ordinary demand system for the calculation of the compensated income suggested by Vartia (1983). The price is decremented by five cent steps from the initial user-pays marginal price to zero so as to derive the compensated income. For each household, the difference between the compensated income and the net income under the rateable value scheme is the option value. This process is repeated for each household. The option values vary between $-\$ 18.25$ and $\$ 1975.30$ with an average of $\$ 152.46$. These dollar figures represent the amount a household is willing to pay in order to avoid the uncertainty associated with the user-pays systems of water charging. The uncertainty factor (option premium) is then incorporated into the probability participation model.

The logit parameter estimates and t-statistics of the probability participation model without the option value are presented in Table 2. The dependent variable is specified as the choice of a userpays charging system over the existing rateable value system. The most important determinants of participation in terms of significance are rateable value $(V A L)$, possession of a dishwasher $(D S H)$, spa $(S P A)$, number of kitchen sinks $(S N K)$, property size $(P R P)$, area of the yard $(Y R D)$, ownership of an in-ground pool $(P B L)$, total number of people in the household $(H L D)$ and ownership of a garbage disposal sytem $(G D P)$. Put differently, the higher the valuation of the property, the more likely the household switches to the user-pays scheme. This also applies to the number of people in the household. As the number of people in the household increases the disposable income may also increase hence the more willing that household is to participate in the user-pays scheme. For the negative coefficients, say, the presence of a dishwasher this implies that the greater the usage of this appliance the more reluctant the household is to participate in the metering scheme. The estimated coefficients for property size and area of the yard are both significant, but opposite in sign. This could be the result of the presence of multicollinearity in these two characteristic variables. 
A number of statistics for joint hypothesis and likelihood ratio tests, and the results of a prediction success table for the dependent variable are also included in Table 2. The likelihoodratio $(L R)$ test can be compared with the critical $\chi^{2}$ value at 5 percent level of significance and 23 degrees of freedom of 35.172. The likelihood-ratio test suggests that the explanatory variables as a group made a significant contribution at 5 percent level in explaining the willingness of households to participate in the alternative metering system. The percentage of right predictions indicates that 98.08 percent of observations can be predicated on the basis of the given vector of explanatory variables.

Table 2: Logit Parameter Estimates of the Participation Model

\begin{tabular}{|c|c|c|c|c|}
\hline \multirow[t]{2}{*}{ Variable } & \multicolumn{2}{|c|}{ Certainty } & \multicolumn{2}{|c|}{ Uncertainty } \\
\hline & Coefficient & t-statistics & Coefficient & t-statistics \\
\hline CONSTANT & -10.7990 & -3.0075 & -13.6450 & -3.2508 \\
\hline VAL & 0.1589 & 6.6639 & 0.2714 & 3.5681 \\
\hline INC & 0.0388 & 0.8362 & 0.0370 & 0.7796 \\
\hline OPT & & & -0.0271 & -1.6905 \\
\hline HLD & 0.6676 & 2.2545 & 0.5896 & 1.9328 \\
\hline PEN & -0.5693 & -1.2031 & -0.5087 & -1.1059 \\
\hline SPR & -0.0855 & -0.2833 & -0.2966 & -0.8794 \\
\hline NTV & -0.0549 & -1.6321 & -0.0621 & -1.7179 \\
\hline VEG & 0.0629 & 1.0401 & 0.0533 & 0.8718 \\
\hline SOI & -0.3838 & -0.8125 & -0.3268 & -0.6812 \\
\hline PRP & -0.0184 & -2.3023 & -0.0172 & -2.1769 \\
\hline YRD & 0.0208 & 2.4760 & 0.0196 & 2.3621 \\
\hline PBL & -0.0001 & -2.4525 & -0.00009 & -2.3406 \\
\hline PAB & -0.00003 & -0.8723 & -0.00003 & -0.6877 \\
\hline SPA & 0.0001 & 3.3905 & 0.0001 & 2.2135 \\
\hline WDG & -0.0039 & -0.6322 & -0.0037 & -0.5699 \\
\hline SHW & -0.7084 & -0.8071 & -0.8382 & -0.9416 \\
\hline BTH & -0.6520 & -0.7450 & -0.5572 & -0.6094 \\
\hline BSN & 1.1537 & 1.4817 & 0.9838 & 1.2076 \\
\hline DUL & 1.1829 & 0.8252 & 1.1664 & 0.7164 \\
\hline WSH & 0.5026 & 0.3675 & 0.7239 & 0.5070 \\
\hline LDY & 0.6798 & 1.1026 & 0.9904 & 1.4938 \\
\hline SNK & -3.9042 & -2.5824 & -3.6811 & -2.5063 \\
\hline DSH & -5.0667 & -3.8627 & -5.2447 & -3.6825 \\
\hline GDP & 2.2948 & 2.0295 & 2.5008 & 2.1253 \\
\hline McFadden $\mathrm{R}^{2}$ & 0.7923 & & 0.8003 & \\
\hline $\ln L$ & -43.897 & & -42.221 & \\
\hline $\ln L(0)$ & -211.38 & & -211.38 & \\
\hline$L R$ & 334.969 & & 338.342 & \\
\hline$\%$ & 0.9808 & & 0.9830 & \\
\hline $\begin{array}{l}\text { Notes: } \ln L(0) \mathrm{i} \\
\text { the null hypoth } \\
\ln L)\end{array}$ & $\begin{array}{l}\text { e maximum } \\
\text { s that all slo }\end{array}$ & $\begin{array}{l}\text { value of the } \\
\text { e coefficien }\end{array}$ & $\begin{array}{l}\text {-likelihood fu } \\
\text { are zero; } L R=\end{array}$ & $\begin{array}{l}\text { ection with } \\
-2(\ln L(0)-\end{array}$ \\
\hline
\end{tabular}


The final part of the analysis involves including the option value $(O P T)$ derived above into the standard model of consumer choice. The results for the logit probability participation model including uncertainty are shown in Table 2. The most significant variables are ownership of dishwashers $(D S H)$, rateable value $(V A L)$, number of kitchen sinks in the household $(S N K)$, yard area $(Y R D)$, in ground pool $(P B L)$, spa $(S P A)$, property size $(P R P)$, garbage disposal $(G D P)$, the total number of people in the household (HLD), native type of vegetation (NTV) and option value $(O P T)$. All parameter estimates are of the same signs as the participation model not including uncertainty. The estimated parameter for the option value is negative and significant at 10 percent implying that households are willing to pay a higher premium to ensure the option of remaining on the rateable value scheme. The significance of the option value reduces the importance of the rateable value variable $(V A L)$. This is due to the fact that the consumers on the rateable value principle are willing to pay a certain amount equivalent to the option value to preserve the right to remain on the user-pays scheme, irrespective of their property valuation.

The likelihood-ratio (LR) test is compared with the critical $\chi^{2}$ value at 5 percent level of significance and 24 degrees of freedom of 36.415. At 5 percent level of significance, the explanatory variables as a group can be used to investigate the willingness of households to participate in the metering system in Brisbane. The original choice model has a percentage of correct predictions of 98.08 percent and the choice model including option value has slightly improved the percentage of correct predictions to 98.30 percent. The option value has increased the correct prediction for the rateable value group. Since the original choice model has a very high predictive power, it is very difficult to compare the goodness of fit of both logit models by examining the percentage of correct predictions. In order to further investigate whether the inclusion of the option value has improved the explanatory power of the choice model, the option value is regressed on the rateable value and the residuals are calculated. The logit equation including the residuals, but omitting the option value and rateable value variables, is estimated. If the t-ratio for the residuals is significant, then the option value has extra explanatory power in the model. The calculated t-ratio for the residual parameter is -3.1341 with the critical value at 5 percent. Hence the option value is a significant explanatory variable in the participation model under uncertainty. 


\section{Concluding Remarks}

The present study uses a binary choice regression model to investigate the influence of property and household characteristics on the likelihood of households selecting a user-pays water charging system over a rateable value system. The case material is drawn from the Brisbane City Council local government area where property owners were initially given the option to remain with the standard rateable value principle of water payment or move to a volumetric user-pays system. The current paper extends empirical work in this area in at least two ways. First, and as far as the authors are aware, it represents the first attempt to derive models of discrete choice in household water charging under uncertainty in Australia.

Second, a key feature of this study is the incorporation of an option value associated with the uncertainty associated with future household water demand which helps, in part, to explain household decisions. The results also indicate that the impact of individual property and household characteristics on the demand for domestic water consumption, and thereby on the choice of a water charging system, vary substantially across a large number of explanatory factors. This has obvious implications for the design of programs to minimise water usage and the creation of alternative water charging schemes.

The most important finding is that consumers may derive benefits that are not associated with the actual use of the water supply, and that these benefits are largely the result of consumer's uncertainty regarding future demand. This provides strong empirical support for the 'flat rate bias' in water metering (Train, 1991). Even where households are not offered a choice between water charging systems, the value of this option may serve to explain at least some of the reticence of households moving to a user-pays water supply. The techniques and results obtained in this study may be useful in analyses of other services where a move to consumption-based charges is considered, including electricity, telecommunications and domestic waste management services.

\section{References}

Arrow, K. J. \& Fisher, A. C. (1974). Environmental preservation, uncertainty and irreversibility. Quarterly Journal of Economics, 88, 313-19.

Bishop, R. C. (1982). Option value: An exposition and extension. Land Economics, 58(1), 1-15.

Cicchetti, C. J. \& Freeman A. M (1971). Option demand and consumer's surplus: Further comment. Quarterly Journal of Economics, 85(3), 528-39.

Freeman, A. M. (1984). The signs and size of option value. Land Economics, 60(1), 1-12.

Freeman, A. M. (1986), Uncertainty and environmental policy: The role of option and quasi-option values. Advances 
in Microeconomics, 4, 153-67.

Graham, D. A. (1981). Cost benefit analysis under uncertainty. American Economic Review, 77, 715-25.

Kridel, D. J., Lehman D. E. \& Weisman, D. L. (1993). Option value, telecommunications demand and policy. Information Economics and Policy, 5, 125-44.

Krutilla, J. V., Cicchetti C. J., Freeman A. M. \& Russell C. S. (1972). Observations on the economics of irreplaceable assets. In A. V. Kneese and B. T. Bower (Eds.), Environmental Quality Analysis: Theory and Methods in the Social Sciences. John Hopkins University Press: Baltimore.

Nieswiadomy, M. L. \& Molina D. J. (1989). Comparing residential water demand estimates under decreasing and increasing block rates using household data. Land Economics, 65, 280-89.

Schmalensee, R. (1972). Option demand and consumer's surplus valuing price changes under uncertainty. American Economic Review, 62, 813-24.

Shilling, J. D., Sirmans C. F. \& Benjamin J. D. (1987). An option pricing with applications to models in real estate. American Real Estate and Urban Economics Association Journal, 15(1), 742-52.

Terza, J. V. \& Welch W. P. (1982). Estimating demand under block rates: Electricity and water. Land Economics, 58, $181-88$.

Terza, J. V. (1986). Determinants of household electricity demand: A two-stage probit approach. Southern Economic Journal, 52, 1131-139.

Train, K. E. (1989). Consumption patterns and self-selecting tariffs. The Review of Economics and Statistics, 62-73.

Vartia, Y. O. (1983). Efficient methods of measuring welfare change and compensated income in terms of ordinary demand functions. Econometrica, 51, 79-98. 